\title{
ANL/ET/PP- -88729
}

Removal of Copper from Carbon-Saturated Steel with an Aluminum Sulfide/Iron sulfide Sulfide Slag*

\section{RECEIVED \\ $\triangle 1 / 16041997$

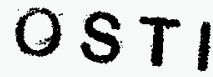

by

Adam Cohen and Milton Blander

Argonne National Laboratory

9700 S. Cass Avenue

Argonne, IL 60439-4838

December 1995

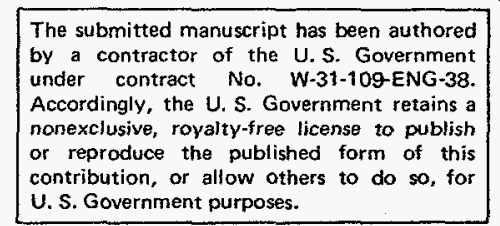

DISCLAIMER

This report was prepared as an account of work sponsored by an agency of the United States Government. Neither the United States Government nor any agency thereof, nor any of their employees, makes any warranty, express or implied, or assumes any legal liability or responsibility for the accuracy, completeness, or usefulness of any information, apparatus, product, or process disclosed, or represents that its use would not infringe privately owned rights. Reference herein to any specific commercial product, process, or service by trade name, trademark, manufacturer, or otherwise does not necessarily constitute or imply its endorsement, recommendation, or favoring by the United States Government or any agency thereof. The views and opinions of authors expressed herein do not necessarily state or reflect those of the United States Government or any agency thereof.

This paper submitted to Metallurgical and Materials Transactions, Carnegie Mellon University, Schenley, PA 15213

*Work supported by the U. S. Department of Energy, LDRD Program, under contract W-31-109-Eng-38. 


\section{DISCLAMMER}

Portions of this document may be illegible in electronic image proinets. Images are produced from the best availabie original document. 


\section{Removal of Copper from Carbon-Saturated Steel with an Aluminum Sulfide/Iron Sulfide Slag}

Adam Cohen and Milton Blander

To determine the effectiveness of a binary slag consisting of aluminum sulfide and iron sulfide on the removal of copper from steel and iron, the distribution coefficient of copper between the slag and a carbon-saturated iron melt was investigated at $1365^{\circ} \mathrm{C}$. The composition of the slag was varied from nearly pure aluminum sulfide to pure iron sulfide. A maximum distribution coefficient of 30 was found, and the copper level in the iron melt was reduced to as low as 0.07 wt.\% with a $4: 1$ ratio of iron to slag.

\section{INTRODUCTION}

Scrap iron and steel has long been considered a resource in the steelmaking industry, and its value is largely determined by its impurity content. As the mini-mills, the major consumers of scrap iron and steel, expand into producing flat-rolled sheet, the demand for high-quality scrap will increase. Of the impurities present in scrap, copper is particularly troublesome because of its role in causing hot shortness. Therefore, the copper content of scrap should be kept below $\approx 0.1$ wt.\%. A method for removing copper from steel could be used to improve the quality of scrap and make it more available for use by mini-mills.

Various methods for removal of copper have been tested; however, no single method has proved to be commercially viable and economical. Because slagging processes are used to remove other impurities from steel, the ideal process for removal of copper would also be slagging. Past 
research on slagging for copper removal has concentrated on binary slags of iron sulfide combined with sodium sulfide; however, the distribution coefficients were too low for commercial processing. This paper presents results from a study in which a binary slag of iron sulfide and aluminum sulfide was used. The use of aluminum sulfide improves the thermodynamics over that in other iron-sulfide-based slags and therefore increases the distribution coefficient of copper.

\section{BACKGROUND}

In general, a slag chemistry must be found in which copper forms a more chemically stable species in the slag than in the iron, and in which the copper species formed is more stable than the iron species that could be formed with the same anion. The sulfide system is one of the few that satisfy this criterion. The following reaction has a standard free energy of change of $\Delta \mathrm{G}^{\circ}=-4.734 \mathrm{kcal} / \mathrm{mol}$ (or an equilibrium constant of $\mathrm{K}_{1}=4.284$ ) at $1638 \mathrm{~K}$ :

$$
\mathrm{FeS}+2 \mathrm{Cu}=\mathrm{Fe}+\mathrm{Cu}_{2} \mathrm{~S}
$$

Using the equilibrium constant for the reaction in Eq. 1, we can derive an equation for the distribution coefficient of copper $\left(\mathrm{L}_{\mathrm{Cu}}\right)$ between the slag and steel.

$$
\mathrm{K}_{1}=\frac{\mathrm{a}_{\mathrm{Cu}_{2} \mathrm{~S}_{\mathrm{Fe}}} \mathrm{a}_{\mathrm{Fe}}}{\mathrm{a}_{\mathrm{FeS}} \mathrm{a}_{\mathrm{Cu}}^{2}} \approx \frac{\gamma_{\mathrm{Cu}_{2} \mathrm{~S}} \mathrm{X}_{\mathrm{Cu}^{+}}^{2}}{\left(\gamma_{\mathrm{FeS}} \mathrm{X}_{\mathrm{FeS}}\right)\left(\gamma_{\mathrm{Cu}} \mathrm{X}_{\mathrm{Cu}}\right)^{2}}
$$




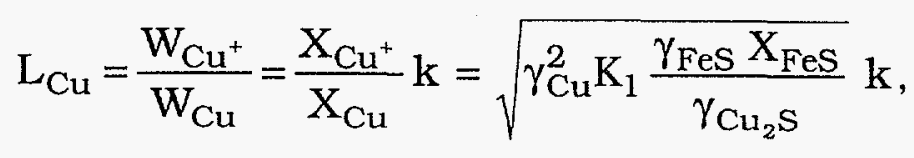

where $\mathrm{k}$ is a constant used to convert mol.\% to wt.\%, $\mathrm{a}_{\mathrm{i}}=$ the activity of $\mathrm{i}, \gamma_{\mathrm{i}}$ $=$ the activity coefficient of $i, X_{i}=$ the mole fraction of $i$, and $w_{i}=$ the weight percent of $i$. Maximizing $\mathrm{L}_{\mathrm{Cu}}$ requires an increase in the activity of iron sulfide, an increase in the activity coefficient of copper, or a decrease in the activity coefficient of cuprous sulfide. The activity coefficient of copper in the steel can be raised by increasing the carbon content or decreasing the silicon content in the steel, ${ }^{1}$ or lowering the melt temperature. However, changes in processing temperature and steel composition have little effect or applicability in a practical sense, and minimizing the activity of iron sulfide, which minimizes the sulfur content in the steel, is desirable. Reduction of the activity coefficient of the cuprous sulfide remains the best way to significantly increase the distribution coefficient for copper between a slag phase and steel.

Work done in determining the enthalpies of mixing $\left(\Delta \mathrm{H}^{\mathrm{m}}\right)$ of binary mixtures of molten salts with a common anion, both charge-symmetrical and -asymmetrical systems, provides a possible basis for reducing the activity coefficient of cuprous sulfide. The negative departures from the ideal of a given salt can be increased significantly (i.e., the activity coefficients can be decreased) in binary mixtures, and the change is a function of both relative cation size and charge. Most of the results have been summarized by Kleppa ${ }^{2,3}$ and Blander. ${ }^{4}$ For charge-symmetrical systems containing two salts, Reiss, Katz, and Kleppa ${ }^{5}$ found the following: 


$$
\Delta \mathrm{H}^{\mathrm{M}}=\mathrm{X}_{1} \mathrm{X}_{2} \Omega(\mathrm{T}, \mathrm{P})\left[\left(\mathrm{d}_{2}-\mathrm{d}_{1}\right) / \mathrm{d}_{1} \mathrm{~d}_{2}\right]^{2}
$$

where the length parameter $d_{i}$ is the sum of the ionic radii of salt $i$, and $\Omega(\mathrm{T}, \mathrm{P})$ is a negative function of temperature and pressure. A cation of a different size than those in a liquid solvent will change the length parameter difference in Eq. 4 and therefore the net Coulombic interactions, especially between the next nearest neighboring cations; the greater the size difference, the larger the change in Coulombic interactions upon mixing and the lower the activity coefficients of the solutes.

For charge-asymmetrical systems, Bland $\mathrm{r}^{4}$ concluded that deviations from ideal behavior in binary systems are related to a function apparently monotonic in the cationic charge $Z$ and $1 / d$ of the solute salt. He also indicated that between the charge and size differences, the charge difference between the solute and solvent cations produced the greater effect. Kleppa ${ }^{6}$ suggested that a negative contribution to the enthalpy of mixing was due to Coulomb effects as well as to the polarization of the common anion caused by the asymmetrical field produced by neighboring cations of different charge. He empirically found that the enthalpy of mixing becomes more negative as the difference in ionic potential ( $\Delta$ IP) between the two cations increases, i.e.,

$$
\Delta \mathrm{IP}=\left|\frac{Z_{1}}{\mathrm{~d}_{1}}-\frac{\mathrm{Z}_{2}}{\mathrm{~d}_{2}}\right|
$$


where $Z_{i}$ is the charge of the ith cation and $d_{i}$ is the length parameter for the ith salt. The greater the difference in ionic potential, the more negative the enthalpy of mixing. Blander also suggests that a change occurs in stabilization of the ligand field of the solute component in the mixture relative to that in the pure salt. ${ }^{4}$ Equation 5 indicates that for a given monovalent solute, the relative stability of the binary mixture can be increased by increasing the charge and decreasing the radius of the solvent cation.

To make cuprous sulfide even more stable relative to ferrous sulfide than the value suggested by Eq. 1, a solvent with a high-charge, small-radius cation, such as aluminum sulfide, could be used to lower the activity coefficient of cuprous sulfide. $^{7}$ The radius of the cuprous ion is $\approx 0.96 \AA$, whereas that of the ferrous ion is $0.75 \AA$. Aluminum sulfide $\left(\mathrm{Al}_{2} \mathrm{~S}_{3}\right)$ contains a polyvalent (+3) cation and its cation radius is $0.45 \AA$. In addition, aluminum sulfide melts at $1100^{\circ} \mathrm{C}$ and does not volatilize at the melting point of the steel. Silicon sulfide could also be considered because the charge of the silica ion is even higher $(+4)$ and its ionic radius is smaller $(\approx 0.38 \AA)$ than that of the aluminum ion. However, the free energy of formation per sulfur ion is similar to that of iron, and use of silicon sulfide would result in a large amount of silicon in the steel.

\section{EXPERIMENTAL SETUP}

The purpose of this study is to find an optimal slag composition for the removal of copper from molten steel. The experiments discussed in this paper concentrate on the binary mixture of aluminum sulfide and iron 
sulfide as a slag. Each test used $90 \mathrm{~g}$ of carbon-saturated steel and $22.5 \mathrm{~g}$ of the slag of interest; a patent ${ }^{7}$ describes experiments that used $10 \mathrm{~g}$ of carbon-saturated steel and $2.5 \mathrm{~g}$ of slag, but we chose the larger samples to allow for continuous stirring of the sample during the test. The steel had an initial composition of 4.1 wt.\% C, $0.37 \mathrm{Cu}, 0.13 \mathrm{Si},(16.5$ at.\% C, $0.28 \mathrm{Cu}$, $0.23 \mathrm{Si}$ ) and trace amounts of $\mathrm{Al}, \mathrm{Ca}, \mathrm{Mo}, \mathrm{Mn}, \mathrm{Ni}, \mathrm{O}, \mathrm{P}, \mathrm{Pb}, \mathrm{S}$, and $\mathrm{V}$. Both the iron sulfide and aluminum sulfide were purchased and the stated purity of each was $>90 \%$; analysis of the aluminum sulfide confirmed the purity, but the iron sulfide was not specifically analyzed. Weighing of the slag was completed in a helium-atmosphere glovebox.

The slag and steel were placed in a high-density graphite crucible, which was then placed inside a hermetically sealed tube assembly consisting of a mullite tube (closed at one end) sealed to a Pyrex cap by a standard O-ring joint. The assembly was evacuated and backfilled with argon gas, which was used as a cover to minimize the reaction of the slag, especially the aluminum sulfide, with air. The assembly was heated in a furnace with molybdenum disilicide resistance heating elements to bring the samples to $1638 \mathrm{~K}$; the samples were maintained at temperature for $3 \mathrm{~h}$, which was determined to be more than sufficient to achieve equilibrium. The programmed temperature of the furnace was maintained to within $5^{\circ} \mathrm{C}$ of the set point with a platinum/platinum-10\% rhodium thermocouple that was also used for temperature readout. The molten steel/slag mixture was continuously stirred with a graphite impeller and stirring rod for the duration of the test.

At the completion of the test, the crucible was either quenched in argon or furnace cooled. The furnace cooling of some samples was performed to 
mimic the cooling method described in the patent; 7 the crucibles were cooled to between 800 and $1,000^{\circ} \mathrm{C}$ and then removed from the furnace and cooled in an argon atmosphere. The quenching was performed so that the samples of slag and steel would be more representative of the slag and steel compositions at $1638 \mathrm{~K}$. Because slag solidifies on cold alumina but steel does not, for some tests, samples of slag were drawn by dipping a cold alumina rod into the melt. Results indicated that the composition of the sampled slag was no different than that of the quenched slag; therefore, sampling was discontinued because it was more difficult to remove the slag samples from the alumina rod than from the quenched graphite crucible.

Samples of both the slag and steel were analyzed for copper and other elements of interest by atomic absorption, at the Charles C. Kawin Co. Oxygen was measured with a Leco oxygen-nitrogen determinator.

\section{RESULTS}

The mole fraction of iron sulfide in the slag $\left(\mathrm{X}_{\mathrm{FeS}}\right)$, the distribution coefficient for copper $\left(\mathrm{L}_{\mathrm{C} u}\right)$, and selected results from steel analyses are summarized in Table I. All samples were analyzed for $\mathrm{Al}, \mathrm{C}, \mathrm{Ca}, \mathrm{Cu}, \mathrm{Fe}, \mathrm{Mg}$, $\mathrm{Mn}, \mathrm{O}$, and S, except the furnace-cooled samples, which were not analyzed for oxygen. The elements of most interest from the steel analysis are listed in Table I, which reveals the copper content in the steel was reduced to $<0.10 \mathrm{wt} . \%(<0.08$ at.\%) for many of the tests. 
The $\mathrm{L}_{\mathrm{Cu}}$ and the sulfur and aluminum content of the steel are plotted in Figs. $1-3$, respectively, as a function of the fraction of iron sulfide in the $\mathrm{Al}_{2} \mathrm{~S}_{3}$ FeS binary mixture.

The $\mathrm{L}_{\mathrm{Cu}}$ as a function of $\mathrm{X}_{\mathrm{FeS}}$, the mole fraction of iron sulfide in the slag (Fig. 1), shows a maximum of $\approx 30$ at $\approx 30 \mathrm{~mol} . \%$ iron sulfide. Test $95-22$ shows a relatively high distribution coefficient, but it is not clear whether this is an aberration.

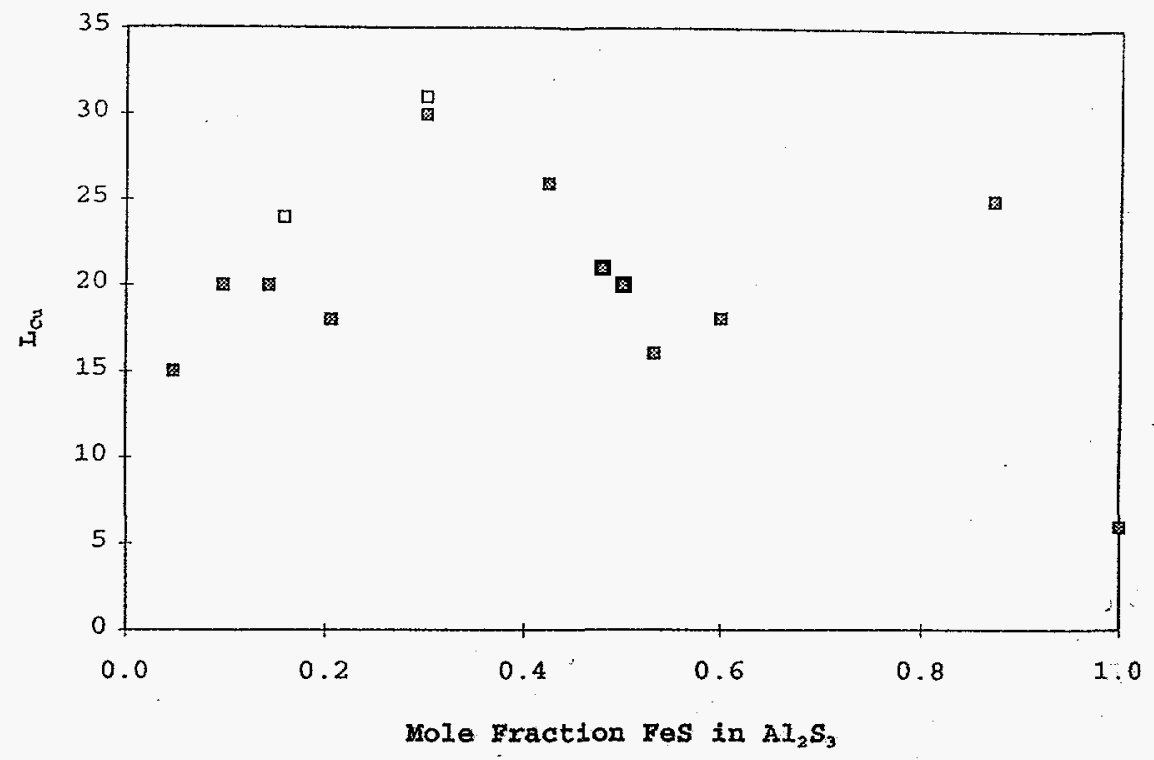

Fig. 1. Distribution coefficient of copper as a function of slag composition. Light squares are results from furnace-cooled tests; darker squares are results from quenching tests.

Figures 2 and 3 show the sulfur and aluminum content in the steel as a function of $\mathrm{X}_{\mathrm{FeS}}$. Aluminum decreases and sulfur increases as the amount of iron sulfide increases. 


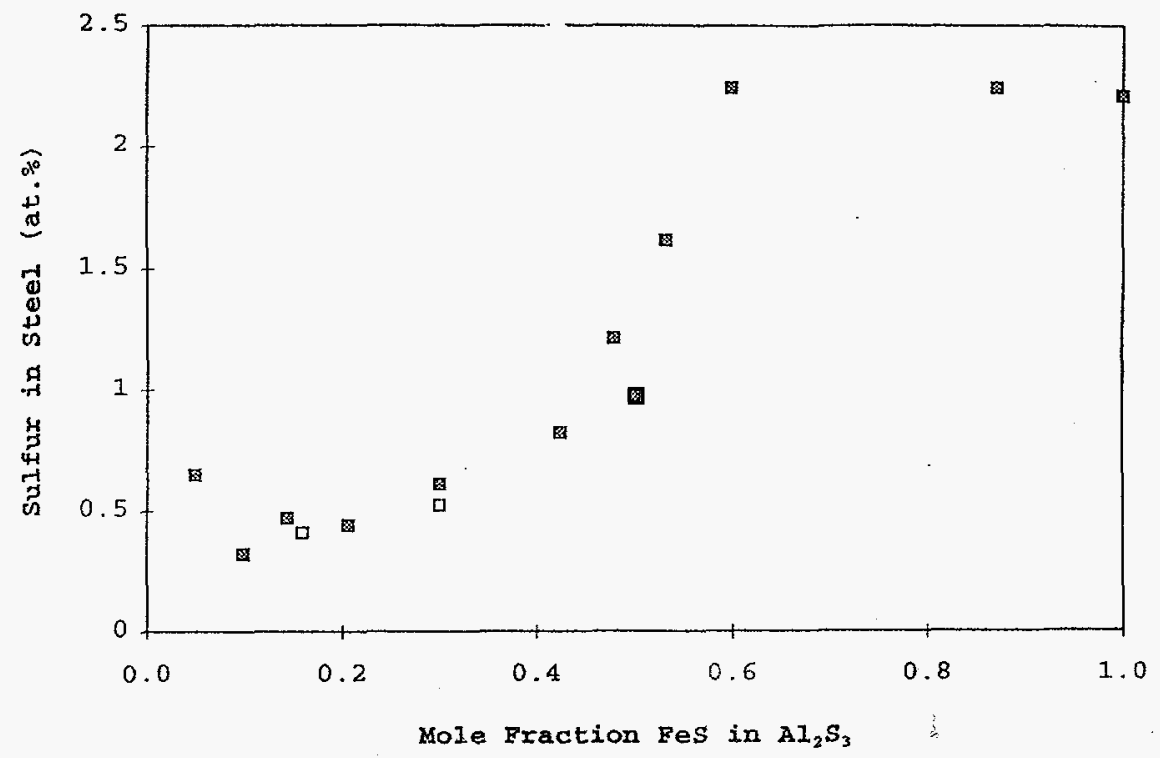

Fig. 2. Sulfur content of steel as a function of iron sulfide concentration in the slag. Light squares are results from furnace-cooled samples; darker squares are results from quenching tests.

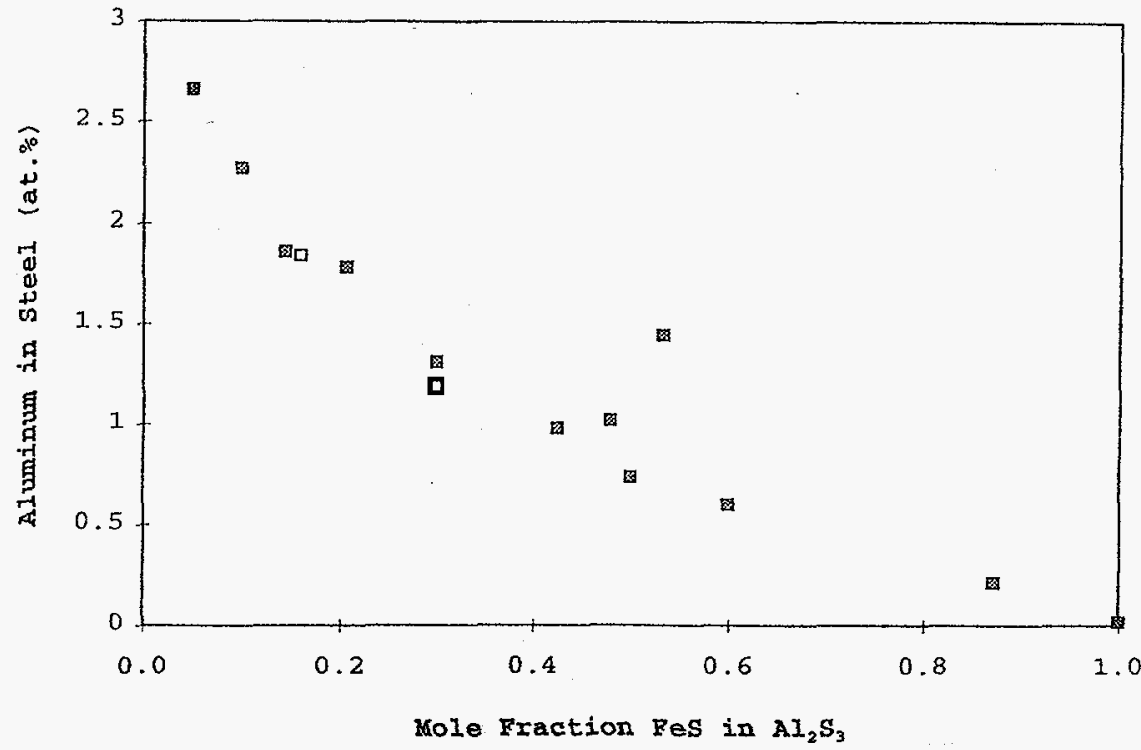

Fig. 3. Aluminum content in steel as a function of iron sulfide concentration in the slag. Light squares are results from furnace-cooled samples; darker squares are results from quenching tests. 
Table I. Mole fraction of iron sulfide in slag, distribution coefficient of copper, and results from steel analysis of a Binary $\left(\mathrm{Al}_{2} \mathrm{~S}_{3}-x \mathrm{FeS}\right)$ Slag at $\mathrm{T}=1638 \mathrm{~K}$.

Steel Analysis (at.\%)

Test

Conditions $\mathrm{X}_{\mathrm{FeS}}$

\begin{tabular}{lccccccc} 
and ID & in slag & $\mathrm{L}_{\mathrm{Cu}}$ & $\mathrm{Al}$ & $\mathrm{C}$ & $\mathrm{Cu}$ & $\mathrm{O}$ & $\mathrm{S}$ \\
\hline $\begin{array}{c}\text { Furnace } \\
\text { Cooled }\end{array}$ & & & & & & & \\
$94-12$ & 16 & 24 & 1.84 & 15.67 & 0.06 & -- & 0.41 \\
$94-11$ & 30 & 31 & 1.19 & 16.77 & 0.05 & -- & 0.52
\end{tabular}

Quenched

\begin{tabular}{rrrrrrrr}
$95-13$ & 5 & 15 & 2.65 & 16.98 & 0.09 & 0.18 & 0.65 \\
$95-14$ & 10 & 20 & 2.26 & 17.67 & 0.07 & 0.04 & 0.32 \\
$94-17$ & 14 & 20 & 1.86 & 16.42 & 0.06 & 0.09 & 0.47 \\
$95-12$ & 21 & 18 & 1.78 & 17.34 & 0.08 & 0.20 & 0.44 \\
$95-09$ & 30 & 30 & 1.31 & 16.81 & 0.05 & 0.06 & 0.61 \\
$94-19$ & 42 & 26 & 0.98 & 16.48 & 0.06 & 0.11 & 0.82 \\
$94-21$ & 48 & 21 & 1.02 & 15.82 & 0.07 & 0.39 & 1.21 \\
$95-10$ & 50 & 20 & 0.73 & 15.90 & 0.07 & 0.08 & 0.97 \\
$94-16$ & 53 & 16 & 1.44 & 15.99 & 0.10 & 0.22 & 1.61 \\
$95-11$ & 60 & 18 & 0.60 & 16.31 & 0.08 & 0.19 & 2.24 \\
$95-22$ & 87 & 25 & 0.21 & 15.77 & 0.08 & 0.36 & 2.24 \\
$94-20$ & 100 & 6 & 0.02 & 14.06 & 0.17 & 0.61 & 2.21 \\
\hline
\end{tabular}




\section{v. DIscussion}

A. Activity Coefficient of Cuprous Sulfide

The $\mathrm{L}_{\mathrm{Cu}}$ varies with slag composition. The maximum value of $\mathrm{L}_{\mathrm{Cu}}$ was $\approx 30$ when the slag contained $30 \mathrm{~mol} \% \mathrm{FeS}$ and $70 \mathrm{~mol} . \% \mathrm{Al}_{2} \mathrm{~S}_{3}$. A maximum $\mathrm{L}_{\mathrm{Cu}}$ value is expected because of two competing effects. First, Eq. 1 indicates that, as iron sulfide content increases, the equilibrium concentration of cuprous sulfide increases. Second, as the iron sulfide content decreases and the aluminum sulfide concentration increases, the activity coefficient of the cuprous sulfide $\gamma_{\mathrm{Cu}_{2} \mathrm{~S}}$ decreases because of the effect of the polyvalent cation $\left(\mathrm{Al}^{3+}\right)$ on the monovalent cuprous cation. Combined, the two effects result in an optimal iron sulfide concentration for copper removal.

To show the effect of aluminum sulfide on the $\gamma_{\mathrm{Cu}_{2} \mathrm{~S}}$, the ratio of the $\gamma_{\mathrm{Cu}_{2} \mathrm{~S}}$ to that of iron sulfide was calculated. Data from Pankratz, et al., ${ }^{8}$ and the JANAF Tables $^{9}$ indicate that the change in free energy of the reaction in Eq. 1 for all of the species present as liquids is $\Delta \mathrm{G}^{\circ}=-4.734 \mathrm{kcal} / \mathrm{mol}$ and $\mathrm{K}_{1}=$ 4.284 at $1638^{\circ}$ of $\mathrm{K}$. Equation 2 can be rearranged to give

$$
\frac{\gamma_{\mathrm{Cu}_{2} \mathrm{~S}}}{\gamma_{\mathrm{FeS}}}=\mathrm{K}_{1} \frac{\mathrm{a}_{\mathrm{Cu}}^{2} \mathrm{X}_{\mathrm{Fe}}^{+2}}{\mathrm{a}_{\mathrm{Fe}} \mathrm{X}_{\mathrm{Cu}^{+}}^{2}}
$$

where $\quad \mathrm{X}_{\mathrm{Fe}^{+2}}=$ cation fraction of iron cations in sulfide, and

$\mathrm{X}_{\mathrm{Cu}^{+}}=$final cation fraction of cuprous cations in sulfide. 
The activity coefficient of copper in a carbon-saturated iron melt was evaluated by Koros and Chipman. ${ }^{1}$ More recently, Wang, et al. ${ }^{10}$ investigated the effect of sulfur on $\gamma_{\mathrm{Cu}}$ in a carbon-saturated steel and derived the following equation:

$$
\log \gamma_{C u}=\log \gamma_{C u}^{\circ}-8.6 X_{C u}-0.429 X_{S}+4.536 X_{S}^{2}-3.228 X_{S}^{3}
$$

The value of $\gamma_{\mathrm{Cu}}^{\circ}$, the activity coefficient for copper in an infinitely dilute solution, largely determines the value of $\gamma_{\mathrm{Cu}}$. Because Wang et al.9 completed the most recent work, their value of $\gamma_{\mathrm{Cu}}^{\circ}=35.5$ at $1673 \mathrm{~K}$ was used and converted to $1638 \mathrm{~K}$ by assuming that the excess free energy, i.e., RTln $\gamma$, is a constant.

For comparison, we calculated the activities for copper in the steel with Thermocalc, ${ }^{11}$ using the analyzed compositions for the steel samples. One calculation considered only carbon, sulfur, copper, and iron in order to compare values with those derived from Eq. 7. The main difference between the values from Thermocalc and those obtained by Wang's method is apparently due to the difference in the value chosen for $\gamma_{\mathrm{Cu}}^{\circ}$. Another Thermocalc calculation added aluminum. The difference between the two Thermocalc calculations was combined with the results from Eq. 7 to yield the desired value for copper activity.

For $\mathrm{a}_{\mathrm{Fe}}$, we used the activity coefficient values for iron in the $\mathrm{Fe}-\mathrm{C}$ system given by Hultgren et al. ${ }^{12}$ Because the values are given for liquid alloys at $1873 \mathrm{~K}$, it was again assumed that $\mathrm{RT} \ln \gamma$ is a constant to extrapolate to $1638 \mathrm{~K}$. 
The mole fractions of ferrous and cuprous ions, the activities for copper and iron, and the activity coefficient ratios calculated with Eq. 6 are given in Table II; liquid is the standard state. The activity coefficient ratio for each furnace-cooled sample was not included in Table II because the assumption that RTln $\gamma$ is constant would not be as valid over the larger temperature range of the experiments.

Table II. Mole fractions of ferrous and cuprous ions, activities of copper and iron, and ratio of activity coefficient of cuprous sulfide to iron sulfide at $\mathrm{T}=1638 \mathrm{~K}$.

\begin{tabular}{llllll}
\hline Test No. & $\mathrm{X}_{\mathrm{Fe}^{+2}}$ & $\mathrm{X}_{\mathrm{Cu}}{ }^{+}$ & $\mathrm{a}_{\mathrm{Fe}}$ & $\mathrm{a}_{\mathrm{Cu}}$ & $\gamma_{\mathrm{Cu}_{2} \mathrm{~S}} / \gamma_{\mathrm{Fes}}$ \\
\hline $95-13$ & & & & & \\
$95-14$ & 0.026 & 0.027 & 0.593 & 0.0142 & 0.15 \\
$94-17$ & 0.052 & 0.030 & 0.593 & 0.0241 & 0.24 \\
$95-12$ & 0.078 & 0.026 & 0.643 & 0.0213 & 0.35 \\
$95-09$ & 0.113 & 0.028 & 0.588 & 0.0314 & 1.04 \\
$94-19$ & 0.176 & 0.031 & 0.662 & 0.0252 & 0.75 \\
$94-21$ & 0.268 & 0.032 & 0.642 & 0.0253 & 1.12 \\
$95-10$ & 0.315 & 0.030 & 0.633 & 0.0183 & 0.79 \\
$94-16$ & 0.334 & 0.033 & 0.618 & 0.0290 & 1.79 \\
$95-11$ & 0.363 & 0.031 & 0.636 & 0.0320 & 2.61 \\
$95-22$ & 0.431 & 0.035 & 0.607 & 0.0261 & 1.69 \\
$94-20$ & 0.774 & 0.047 & 0.638 & 0.0279 & 1.83 \\
\hline
\end{tabular}

The ratio of activity coefficients is plotted in Fig. 4 as a function of the initial iron cation fraction in the slag. As iron sulfide decreases (i.e., aluminum 
sulfide increases), the activity coefficient ratio decreases to a value of $\approx 0.15$. At high iron sulfide concentrations, the ratio approaches the activity coefficient of cuprous sulfide in pure iron sulfide.

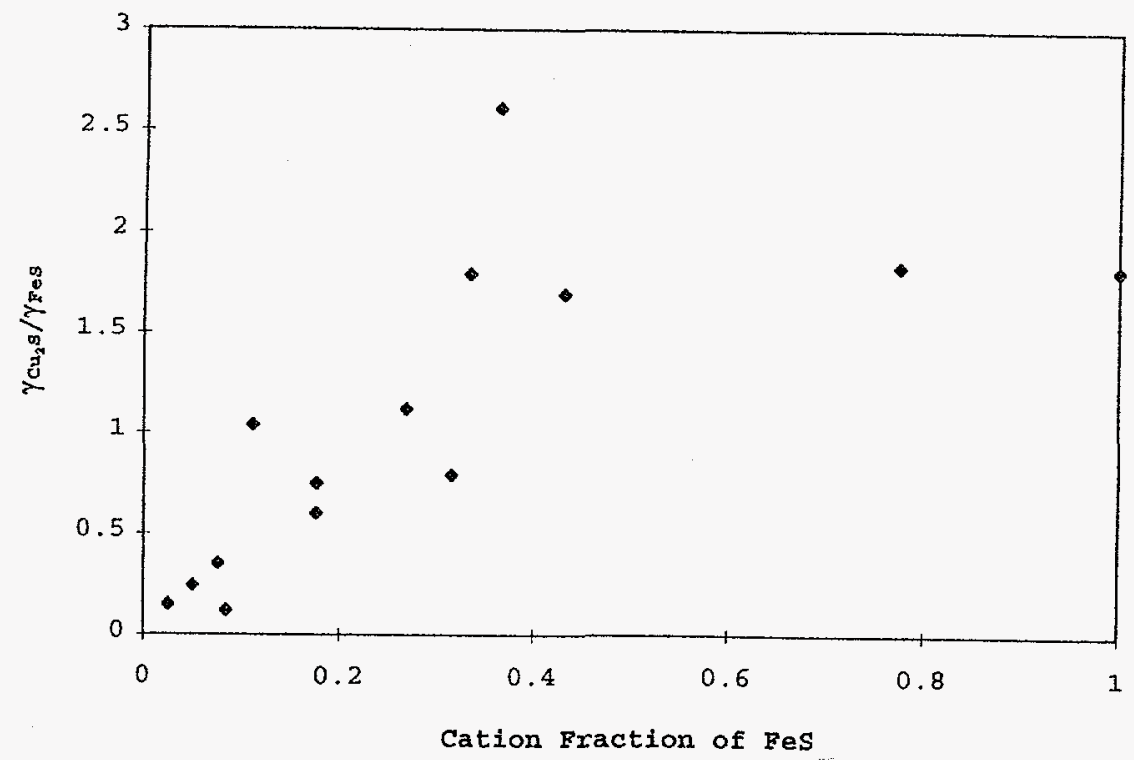

Fig. 4. Ratio of activity coefficient of cuprous sulfide to that of iron sulfide as a function of cation fraction of iron sulfide.

B. Sulfur in Steel

The sulfur content of the steel increases with iron sulfide concentration in the slag (see Fig. 2), and the steel apparently becomes saturated with sulfur at about $\mathrm{X}_{\mathrm{FeS}}=0.6$; this may indicate a miscibility gap in the $\mathrm{Al}_{2} \mathrm{~S}_{3}-\mathrm{FeS}$ system. For the melts in this study, $a_{\mathrm{Fe}}$ is a constant; therefore, $\mathrm{a}_{\mathrm{Fes}}$ is proportional to as. At low concentrations of iron sulfide, the concentration of sulfur in steel again levels off. The low asymptotic value is due to the activity of sulfur from the dissociation of aluminum sulfide at $1638 \mathrm{~K}$. The contribution to the sulfur activity by iron sulfide would approach zero as the aluminum sulfide increases. Also, from the shape of the curve, it can be 
concluded that the activity coefficient of iron sulfide decreases as the aluminum sulfide increases to a value of $<1$ at infinite dilution.

\section{Aluminum in Steel}

The aluminum content of the steel decreases as the iron sulfide content in the slag increases (see Fig. 3) for two reasons, both related to the fact that the square of the activity of aluminum in the melt is proportional to the activity of aluminum sulfide and inversely proportional to the cube of the activity of the sulfur. First, as the activity of iron sulfide increases, the activity of sulfur increases, and the activity of aluminum decreases. Second, as the concentration of iron sulfide increases, the activity of aluminum sulfide, and thus of aluminum, decreases. Combined, the two effects lead to a decrease in the concentration of aluminum in the steel. The first effect is the larger of the two, especially at higher iron sulfide concentrations, and apparently results in the change in slope seen in Fig. 3.

Comparing Fig. 2 and 3 indicates an apparent solubility product for sulfur and aluminum, which is equivalent to the activity of the sulfur cubed times the activity of the aluminum squared. Because we do not have information on the concentration dependence of the activity coefficients, the activities for aluminum and sulfur were calculated with the Thermocalc program for the metal compositions given in Table 1 . The solubility product $\mathrm{a}_{\mathrm{Al}}^{2} \mathrm{a}_{\mathrm{S}}^{3}$ is plotted in Fig. 5 as a function of the mole fraction of $\mathrm{FeS}$ in $\mathrm{Al}_{2} \mathrm{~S}_{3}$. From an iron sulfide content of $10 \mathrm{~mol} \%$ up to about $50 \mathrm{~mol} \%$, the saturation point for sulfur, the apparent solubility product is constant. The fact that the product is not complicated in that range of iron sulfide indicates a simple 
chemistry for the effect of the binary slag composition on the aluminum and sulfur contents in the steel. In other words, the iron sulfide concentration governs the sulfur content and the solubility product determines the aluminum content in the steel.

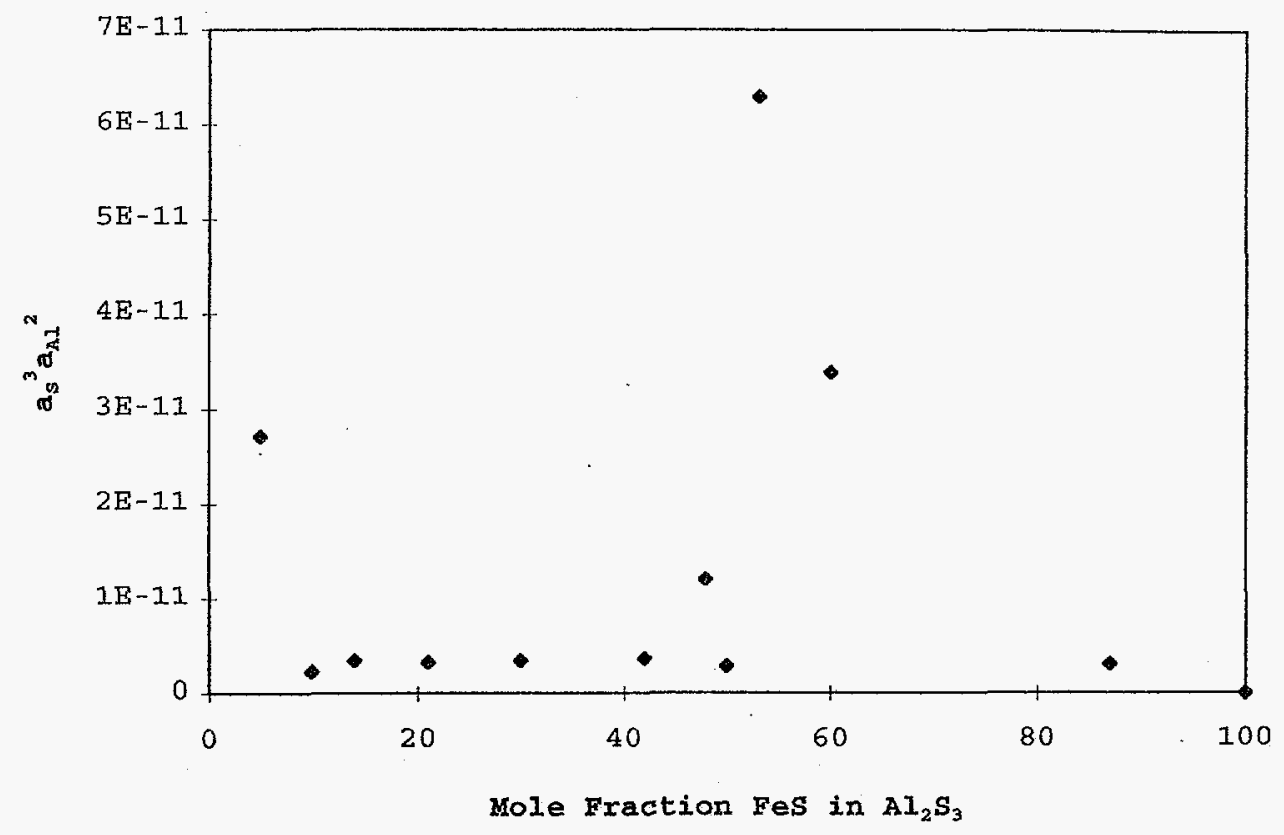

Fig. 5 Product of the sulfur activity cubed times the aluminum activity squared as a function of iron sulfide concentration in the slag. A constant solubility product is indicated from $\mathrm{X}_{\mathrm{FeS}}=10$ to 50 .

\section{Effect of Oxygen on Distribution Coefficient}

As discussed in the Experimental Setup Section, the apparatus was designed to minimize the reaction between slag and air. Given the free energies of formation for the possible metathetical reactions that involve oxygen, it is likely that most of the oxygen in the apparatus would react with aluminum sulfide to form alumina, and the remainder would react with iron sulfide to 
yield iron sulfate and iron oxide. Both reactions would result in a reduction in the expected value for the distribution coefficient. As the oxygen activity increases, the system approaches an oxide slag system in which the equilibrium constant for iron oxide being reduced by copper is extremely low (i.e., $\approx 10^{-4}$ ). Although Table I does show a small variation in the oxygen concentration in the steel, no definite relationship can be derived between the oxygen activity and the distribution coefficient from the small amount of data available.

\section{CONCLUSIONS}

The removal of copper from molten ferrous alloys is possible with the use of a sulfide-based slag, Several conclusions can be drawn from the results of this study, in which varying compositions of iron sulfide and aluminum sulfide were used as a slag:

1. The presence of aluminum sulfide reduces the activity coefficient of cuprous sulfide because the effects of the trivalent aluminum ion are greater on the activity coefficient of the monovalent cuprous cation than on the activity coefficient of the divalent ferrous cation.

2. The distribution coefficient for copper $\left(L_{\mathrm{C} u}\right)$ varies with slag composition. The maximum value of $\mathrm{L}_{\mathrm{Cu}}$ was $\approx 30$ at a composition of 30 mol.\% FeS and $70 \mathrm{~mol} \% \mathrm{Al}_{2} \mathrm{~S}_{3}$. As the iron sulfide content of the molten aluminum sulfide increases from zero, the equilibrium concentration of cuprous sulfide increases. However, as the iron sulfide concentration increases, the activity coefficient of cuprous sulfide 
increases faster than that of iron sulfide because the effect of the polyvalent cation $\left(\mathrm{Al}^{3+}\right)$ on the monovalent cuprous cation is greater than it is on the divalent ferrous cation. Combined, the two competing effects result in a maximum at 30 mol.\% FeS.

3. A copper content in steel of $\approx 0.4 \mathrm{wt} . \%$ can be reduced to below 0.10 wt.\% (actually $0.07 \mathrm{wt} \%$ in our experiment at this composition) by using a slag with a composition of $30 \mathrm{~mol} \% \mathrm{FeS}$ and $70 \mathrm{~mol} . \% \mathrm{Al}_{2} \mathrm{~S}_{3}$, with a weight one-fourth of that of the metal.

Future tests in the study will concentrate on the effect of adding other sulfides, such as calcium sulfide and magnesium sulfide, to the $\mathrm{Al}_{2} \mathrm{~S}_{3}-\mathrm{FeS}$ slag. Initial results indicate that the addition of magnesium sulfide may increase the distribution coefficient for copper. Other additives may also be considered.

\section{ACKNOWLEDGMENTS}

The authors thank everybody who assisted in completing this experimental effort. They also thank Argonne National Laboratory for providing the funding to complete the work. 


\section{REFERENCES}

1. P. J. Koros and J. Chipman, J. Metals, 206, 1956, pp. 1102-1104.

2. O. J. Kleppa, Thermodynamics in Geology, NATO Advanced Study Institutes Series C, D. G. Fraser, ed. (D. Reidel Publishing Co., Dordrecht, Netherlands, 1977), pp. 279-299.

3. O. J. Kleppa, Ann. Rev. Phys. Chem., 16, 1965, pp. 187-212.

4. M. Blander, Molten Salt Chemistry, M. Blander, ed. (Interscience Publishers, J. Wiley \& Sons, New York, 1964).

5. H. Reiss, J. L. Katz, and O. J. Kleppa, J. Chem. Phys., 36 [1], 1962, pp. 144-148.

6. O. J. Kleppa, J. Phys. Chem., 66, 1962, pp. 1668-1671.

7. M. Blander and S. N. Sinha, U.S. Patent No. 4,925,488, May 15, 1990.

8. L. B. Pankratz, J. M. Stuve, and N. A. Gokcen, Thermodynamic Data for Mineral Technology, Bulletin 677, U.S. Dept. of Interior, Bureau of Mines, 1984.

9. M. W. Chase, Jr., C. A. Davies, J. R. Downey, Jr., D. J. Frurip, R. A. McDonald, and A. N. Syverud, JANAF Thermochemical Tables, 3rd Ed. Part II, Cr-Zr, American Chemical Society and American Institute of Physics for the National Bureau of Standards, 1986. 
10. C. Wang, T. Nagasaka, M. Hino, and S. Ban-Ya, ISIJ Int., 31, 1991, pp. $1300-1308$.

11. B. Sundman, B. Jansson, and J. A. Andersson, CALPHAD, 9, 1985, pp. 153.

12. R. Hultgren, P. D. Desai, D. T. Hawkings, M. Gleiser, K. K. Kelley, Selected Values of the Thermodynamic Properties of Binary Alloys, (American Society for Metals, Metals Park, OH, 1973), pp. 477-488. 